\title{
EMR+: A Novel Bimanual Endoscopic Technique for En Bloc Resection of a Proximal Colon LSL-NG/PD Lesion Using a New External Additional Working Channel Device
}

\author{
Vincent Zimmer ${ }^{\mathrm{a}, \mathrm{b}}$ Elke Eltze ${ }^{c}$

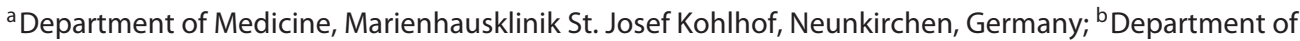 \\ Medicine II, Saarland University Medical Center, Saarland University, Homburg, Germany; ${ }^{C}$ Institute of \\ Pathology Saarbrücken-Rastpfuhl, Saarbrücken, Germany
}

\section{Keywords}

Endoscopic mucosal resection - Colorectal lesion .

Colonoscopy · Colorectal adenoma $\cdot$ Screening

colonoscopy $\cdot$ En bloc resection

EMR+: Uma nova técnica endoscópica bimanual para resseção em bloco de uma lesão LSL-NG/PD do cólon proximal usando um dispositivo externo para canal de trabalho adicional

\section{Palavras Chave}

Colonoscopia · Adenoma coloretal · Lesão coloretal ·

Resseção em bloco - Resseção endoscópica da mucosa .

Colonoscopia de rastreio

A 90-year-old female patient underwent ileocolonoscopy for iron-deficiency anemia. In the proximal colon, an estimated $22-\mathrm{mm}$ non-granular laterally spreading lesion with discrete areas of pseudo-depression (LSL-
NG/PD), Paris IIa+IIc, emerged across a fold (Fig. 1a). After submucosal injection of an indigocarmin-suprarenin mixture (Fig. 1b), optical assessment including image-enhanced endoscopy using linked colour imaging (Fig. 1c) and blue laser imaging (Fig. 1d) suggested distorted vessel and surface pattern, tentatively classified as analogous to NICE type 3 lesion (NBI International Colorectal Endoscopic classification). Likewise, pseudo-depressed appearing areas were thus highlighted. Due to concerns of advanced neoplasia and known higher risks of incomplete resections, when applying conventional endoscopic mucosal resection (EMR) technique in across-fold lesions, we opted for additional-working channel (AWC)-assisted resection, alternatively designated EMR+, as a novel endoscopic tool for en bloc resections of difficult colorectal lesions [1]. In consequence, an AWC device (Ovesco Endoscopy, Tübingen, Germany) was externally mounted onto the scope's tip with the external channel oriented contralaterally to the scope's working channel for maximum triangulation [2] (Fig. 1e, f). karger@karger.com www.karger.com/pjg

Karger $\stackrel{\text { ' }}{5}$ BOPEN ACCESS (c) 2021 Sociedade Portuguesa de Gastrenterologia Published by S. Karger AG, Basel

This is an Open Access article licensed under the Creative Commons Attribution-NonCommercial-4.0 International License (CC BY-NC) (http://www.karger.com/Services/OpenAccessLicense), applicable to the online version of the article only. Usage and distribution for commercial purposes requires written permission.
Vincent Zimmer

Department of Medicine, Marienhausklinik St. Josef Kohlhof Klinikweg 1-5

DE-66539 Neunkirchen (Germany)

vincent.zimmer@gmx.de 

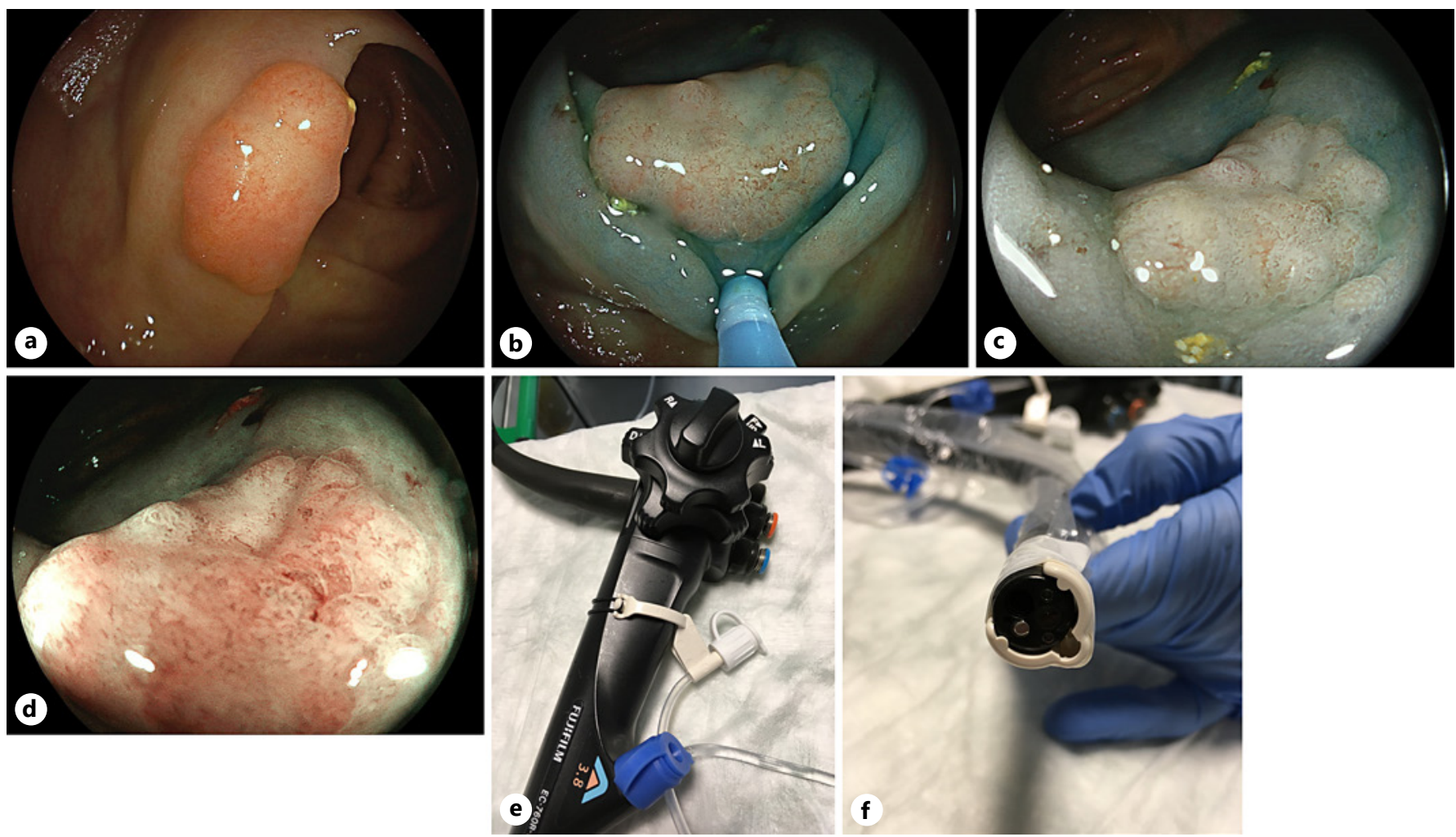

Fig. 1. a An estimated 22-mm colorectal lesion across a proximal colon fold. b After submucosal injection, pseudo-depressed areas emerged, and the lesion was classified as an LSL-NG/PD, Paris IIa+IIc. c, d Distorted vessel structure and amorphous surface pattern were appreciated on linked colour (LCI) and blue laser imaging (BLI), respectively, raising concern of potentially advanced

Next, a $25-\mathrm{mm}$ snare was introduced through the scope's working channel, and an anchor through the AWC to lift up the lesion as a modified "grasp-and-snare" approach. After coordinated anchor-related mobilization of the lesion (Fig. 2a), we performed judicious forward-pushing movements combined with slow, but finally tight snare closure (Fig. 2b). This is referred to as the "push-back" technique as a sine qua non for EMR+ resections to limit risk of muscularis propria capture and, thus, perforation. Finally, the tightly snared lesion is then resected en bloc by routine electrocautery settings as in standard EMR procedures, e.g., EndoCutQ, effect 2, duration 4, interval 3 (Fig. 2c). Visualization of the resection site excluded deep mural injury (DMI) and/or perforation (Fig. 2d). Due to right-sided localization, we performed full defect closure involving three hemoclips to reduce risk of delayed bleeding. Of interest, final pathology indicated an unexpectedly favourable result for the patient with low-grade intraepithelial neoplasia only with confirmed R0 status. neoplasia (tentatively classified as analogous to a NICE type 3 lesion). e Ex vivo demonstration of the additional working channel (AWC) device (Ovesco Endoscopy, Tübingen, Germany) attached to the scope's shaft (valve) (c) and tip (AWC) (d). Note AWC mounted contralateral to the scope's working channel to fully exploit triangulation potential.

AWC-assisted endoscopic resection, or EMR+, is a novel promising tool to increase en bloc resection rates of various upper and lower GI tract lesions, including flat, larger-than-20-mm, difficult-to-access lesions as well as lesions suspicious for (limited) submucosal infiltration, etc., relying on bimanual triangulation within the operative field [3].

\section{Statement of Ethics}

The patient has given written informed consent for publication (including publication of images).

\section{Conflict of Interest Statement}

The authors have no conflicts of interest to declare.

GE Port J Gastroenterol 2022;29:148-150 

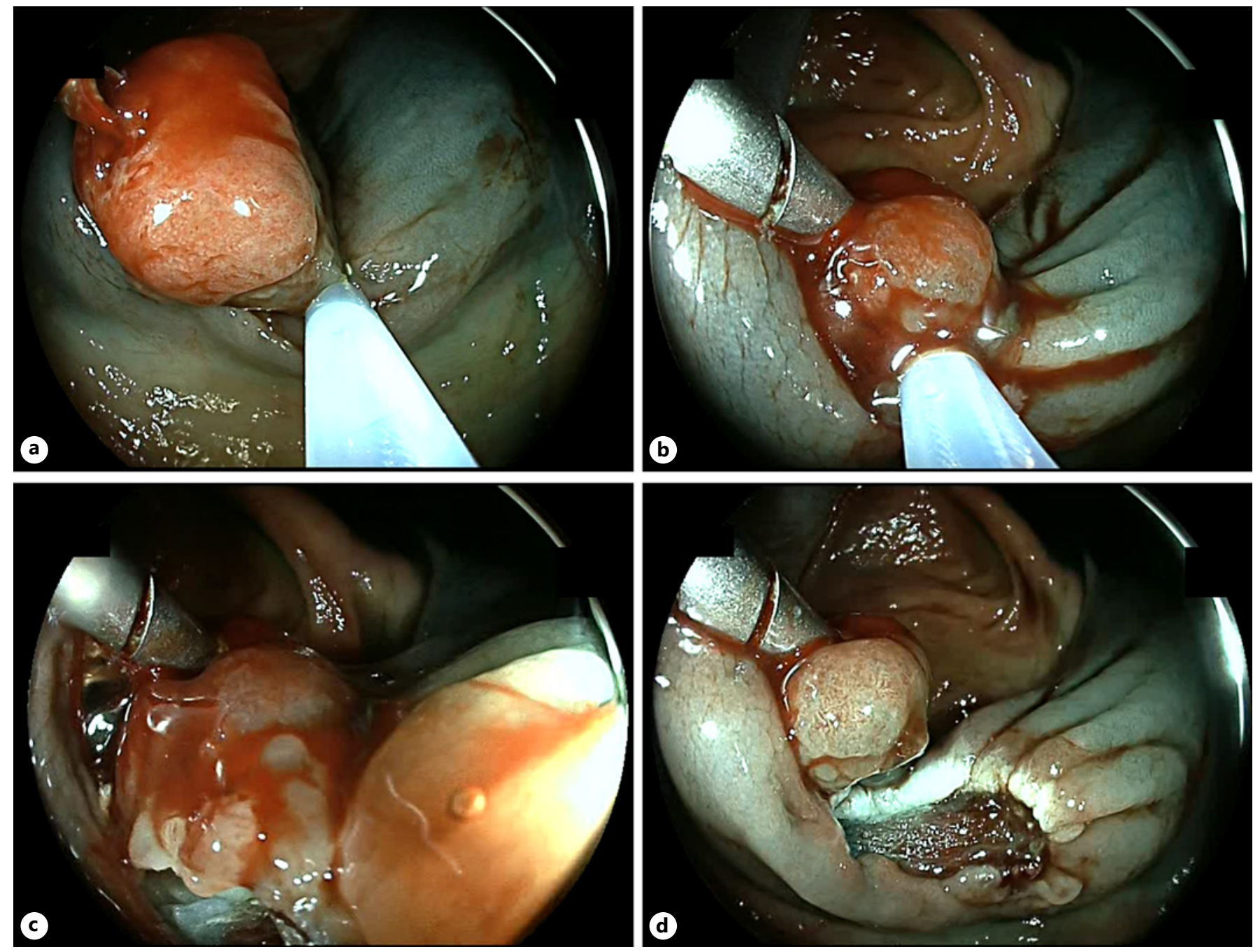

Fig. 2. a An anchor through the AWC lifts up the lesion into a 25$\mathrm{mm}$ snare in a modified "grasp-and-snare" fashion. b Coordinated mobilization and pushing back using the anchor prior to full and tight snare closure to avoid muscularis propria entrapment/perfo-

ration ("push-back" technique), followed by electrosurgical resection using standard EMR settings (c). d Evaluation of the resection site excluding deep mural injury/perforation.

Funding Sources

No funding.

\section{References}

1 Minamino H, Nagami Y, Shiba M, Hayashi K, Sakai T, Ominami M, et al. Colorectal polyps located across a fold are difficult to resect completely using endoscopic mucosal resection: A propensity score analysis. United European Gastroenterol J. 2018 Dec;6(10): $1547-55$.
2 Sportes A, Cfm J, Gromski MA, Koehler P, Seif Amir Hosseini A, Kauffmann P, et al. Novel modified endoscopic mucosal resection of large GI lesions ([\{GT\}] $20 \mathrm{~mm}$ ) using an external additional working channel (AWC) may improve $\mathrm{R} 0$ resection rate: initial clinical experience. BMC Gastroenterol. 2020 Jun;20(1):195.

\section{Author Contributions}

V.Z.: clinical care, drafting and finalization of manuscript. E.E.: pathology, revision and approval of manuscript.
3 Walter B, Schmidbaur S, Krieger Y, Meining A. Improved endoscopic resection of large flat lesions and early cancers using an external additional working channel (AWC): a case series. Endosc Int Open. 2019 Feb;7(2):E298301. 